\title{
ANÁLISE DE POLÍTICA PÚBLICA: AÇÃO 8874 DO MINISTÉRIO DAS CIDADES
}

\author{
Samuel Samuel Martins ${ }^{1}$
}

${ }^{1}$ Licenciado e Bacharel em Geografia - UFRGS. Mestre em Geografia - UFRGS. E-mail: samuel.ufrgs@gmail.com

Recebido em 07/2013. Aceito para publicação em 10/2013.

Versão online publicada em 12/09/2014 (http://seer.ufrgs.br/paraonde)

\begin{abstract}
Resumo - A ação 8874 do Ministério das Cidades foi lançada em 2012 para ajudar a promover o ordenamento territorial através de planejamento e gestão urbanos impulsionados por estados e municípios, que são estimulados a qualificar planos diretores, gestão do solo e planejamento territorial. No entanto, uma série de elementos precisa ser melhor estudada para que seja possível avaliar se as ideias produzidas centralmente e as aspirações locais serão mutuamente contempladas pelos benefícios advindos dos recursos que a ação destina. A metodologia aplicada prevê a discussão teórica sobre o tema da política pública em questão, escolhendo-se autores vinculados aos temas relacionados, com o objetivo de estimular a discussão sobre formas de direcionamento das atividades de planejamento. Este ensaio promove a discussão acerca de tópicos como os atores envolvidos, a participação, interesses setoriais, coesão territorial e escalas de abordagem, revelando a necessidade de articulações e construções coletivas prévias à adesão pelos entes federativos.
\end{abstract}

Palavras-chave: : planejamento territorial, gestão urbana, desenvolvimento, políticas públicas.

\section{INTRODUÇÃO}

0 ordenamento territorial voltado à gestão urbana recebeu grande impulso com o Estatuto da Cidade, que já completou mais de uma década orientando a política urbana no território brasileiro. Oliveira (2001) destaca que, através dos instrumentos da política urbana, o Estatuto da Cidade fixa diretrizes que promovem o desenvolvimento das cidades brasileiras de acordo com pressupostos constitucionais e norteadores das ações públicas para a área. Dentre os instrumentos, podemos destacar os planos de ordenação do território e desenvolvimento, os sistemas de planejamento, os institutos jurídicos, políticos, tributários e financeiros, os estudos de impacto ambiental e de vizinhança, tudo sempre contemplando as variadas escalas.

Prioridade para os estudos de uso e ocupação do solo recebe o sistema de planejamento, em especial o municipal. 0 instrumento de planejamento mais relacionado com este viés é o Plano Diretor, onde se faz necessária a proposição de alternativas teóricas (ideológicas) e metodológicas mais eficazes, como afirma Nygaard (2005). A neutralidade política e ideológica na concepção dos planos diretores produzidos ao longo do século passado é criticada pelo autor, assim como seu conteúdo tecnicista aparentemente isento, que esconde imposições e visões de cidade que reproduzem a exclusão de determinados grupos da sua discussão. Portanto, é necessário defender a "[...] concepção de planos diretores como instrumentos de construção da cidadania, de efetiva e ampla participação social, de implementação dos direitos humanos e de profunda qualificação do ambiente urbano [...]" (NYGAARD, 2005, p. 45).

O presente texto aborda uma ação do Ministério das Cidades que se traduz em uma política que visa ao ordenamento territorial através de apoio às atividades de planejamento e gestão urbanos conduzidos por estados e municípios. Trata-se da Ação 8874: Apoio ao Planejamento Territorial e à Gestão Urbana Municipal e Interfederativa, conduzida pelo Departamento de Políticas de Acessibilidade e Planejamento Urbano, subordinado à Secretaria Nacional de Acessibilidade e Programas Urbanos. É, desta forma, uma política territorial impulsionada pelo governo federal para auxiliar os estados e, principalmente, os municípios a produzir estudos, formações, capacitações e metodologias aplicáveis à elaboração de planos diretores, gestão do solo e planejamento territorial objetivando, em pano de fundo, a sustentabilidade e a redução de desigualdades sociais, dependente de encaminhamento de propostas pelos interessados. A portaria ${ }^{\circ}$ 87/2012 do Ministério das Cidades aprovou o manual para apresentação de propostas com todas as orientações necessárias detalhadas.

Esta política pública aplicada integra a Sistemática 2012, que apresenta manuais para apresentação de propostas que visam à busca de recursos para reabilitação de áreas centrais, planejamento territorial e gestão urbana, além de transporte e mobilidade urbana. 
Causa certo estranhamento a quantidade de programas oferecidos, em número bastante reduzido e ainda não muito interconectados. De início, vale ressaltar que a expectativa prévia à leitura do manual era muito maior, dada a importância estratégica do Ministério das Cidades e a pertinência dos temas envolvidos em sua competência de atuação.

À luz de algumas considerações desenvolvidas por autores que tratam sobre tópicos relacionados ao planejamento, ao desenvolvimento, aos poderes envolvidos e ao ordenamento, pretende-se neste ensaio instigar futuros questionamentos pertinentes (e necessários) que podem ser importantes para o aprimoramento da atuação dos entes estatais na promoção do desenvolvimento urbano.

Assim, os objetivos, antes de se pensar em avaliar condutas operacionais ou resultados da aplicação dos recursos vinculados à ação de apoio ao planejamento e gestão oferecida pelo poder central, relacionam-se com uma discussão teórica acerca da proposta da ação. Estes marcos teóricos, contextualizados no estudo do objeto em questão, constituem-se naquilo que se pretende alcançar nesta etapa da avaliação desta política pública.

Não há procedimentos operacionais propriamente ditos (estudo de casos concretos, coleta de dados, atividades de campo ou produções cartográficas) neste trabalho, apenas a análise teórica de uma política pública escolhida por interesse acadêmico e pela disponibilidade facilitada para acesso ao material de divulgação.

Portanto, o método empregado limita-se à análise daquilo que se pode obter para avaliação diretamente no canal de origem. Neste caso, todas as informações necessárias foram colhidas diretamente no sítio eletrônico do Ministério das Cidades, onde é encontrado o manual da ação 8874 para download. Os procedimentos seguidos para a elaboração do ensaio são guiados pelas contribuições de autores escolhidos de acordo com sua vinculação a diferentes tópicos relacionados à temática.

A ação 8874, uma vez elaborada, lançada e em execução, é, sem dúvida, um instrumento importante para a qualificação das atividades de planejamento urbano desenvolvidas nos estados e municípios. Incorporando os avanços na área a partir do Estatuto da Cidade, era de se imaginar que os resultados de sua aplicação somente poderiam ser positivos. Em vários aspectos, isto é verdade. Porém, isso não significa que as contribuições do apoio técnico sejam neutras e representantes da única possibilidade de atuação, principalmente por parte do Estado.

Um caso sintomático de que as ações de planejamento e gestão carecem de resultados melhores ocorreu este ano, com a profusão de protestos por todo o país. Tanto nas grandes cidades como, em seguida, pelo interior, as grandes manifestações reivindicatórias ocorridas em 2013 (Figura 1) tiveram alguns elementos em comum e que permaneceram como constantes em praticamente todos os episódios.

\section{Figura 1 - Protesto em Porto Alegre (17/06/2013)}

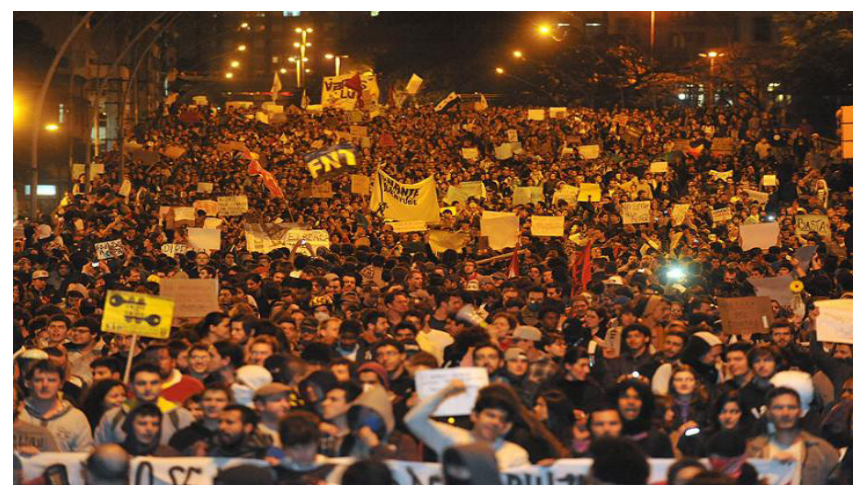

Fonte: Notícia no sítio eletrônico do jornal Correio do Povo: "Protesto paralisa centro de Porto Alegre".

Disponíveem: <http: / / www.correiodopovo.com.br/ Noticias/?Noticia $=501077>$

Acesso em: 18 jun 2013.

Três desses elementos são destacados abaixo:

0 primeiro era o sentimento geral de insatisfação. Não com a vida que se leva, mas com múltiplos detalhes do dia-a-dia, como o transporte público, os serviços essenciais, a segurança, o controle da corrupção, enfim, um sem-número de retalhos de um conjunto que, para as pessoas, não se encontra no nível de qualidade desejado.

O segundo era o direcionamento: a voz (e também as aglomerações) se dirigia para o poder público, na tentativa de uma interlocução forçada devido ao sentimento de distanciamento deste.

0 terceiro, mais do que por exposição, surge pela ausência: não havia queixas quanto à capacidade técnica dos gestores públicos, no que se refere às suas atribuições e à capacidade de enfrentamento dos problemas da sociedade. Muito do barulho que se produziu era eco da incompreensão ou contrariedade com a orientação mais subjetiva das opções técnicas de planejamento e gestão, cujos resultados eram insatisfatórios.

Os reflexos deste componente ideológico são as condições encontradas para o desenrolar do cotidiano nas cidades, e mesmo que o despreparo técnico seja a causa da atuação deficiente do Estado em algumas frentes, o recado foi dado: existe o desejo de expressar opinião, e isso não diz respeito somente à participação popular, esta já experimentada setorialmente. Orçamentos, planejamentos e conselhos participativos são avanços democráticos no sentido da escolha, mas a autonomia e a construção cidadã das diretrizes ainda não superaram o distanciamento da construção técnica relativamente aos anseios da população.

Então, pode-se partir, inicialmente, da discussão sobre as vinculações ideológicas da emanação de diretrizes desde o poder central. 0 planejamento, assim, pressupõe a necessidade de uma forma homogeneizante, sugerindo, desta forma, algum grau de neutralidade?

Sempre que possível, é interessante lembrar que 
mesmo metodologias ou estratégias de planejamento e gestão podem ter origem endógena, apesar da falta de conhecimento técnico aprofundado por parte dos grupos sociais envolvidos ou afetados direta e indiretamente.

\section{Planejamento e desenvolvimento}

A prevalência doutrinária da técnica e a pretensa neutralidade do planejamento urbano também são rebatidas por Souza (2010). Ele entende que o planejamento e a gestão urbanos não podem prescindir do tratamento científico. Porém, os valores envolvidos dependem em grande parte das relações que incluem os interesses das classes envolvidas no processo de construção e ocupação do espaço urbano. Relações essas que podem ser associativas, solidárias, mas, principalmente, tensas e conflituosas. Portanto, relações políticas, de poder e dominação, estão refletidas nos instrumentos de planejamento, tanto mais quanto melhor aparelhada à estrutura do Estado, de acordo com determinados grupos sociais.

O foco do planejamento, desta forma, está no desenvolvimento. Este tem sido confundido com desenvolvimento econômico, enquanto Souza (2010) defende que o significado correto é "mudança social positiva". Portanto, existe uma limitação na compreensão do significado de desenvolvimento, e a consequência disso é a limitação no entendimento do planejamento, com sérias implicações práticas.

Para que sejam superadas essas limitações, Souza propõe incorporar a noção de autonomia ao desenvolvimento, o que conduziria à sua associação com a ideia de mudança. 0 desenvolvimento, encarado assim, converte-se em "desenvolvimento sócio-espacial".

Para que o desenvolvimento sócio-espacial seja levado à realidade da população, o autor indica dois objetivos que precisam ser buscados, representando os resultados da incorporação das ideias de mudança social positiva e autonomia às diretrizes teóricas das ações de planejamento. 0 primeiro é a melhoria da qualidade de vida. Este está fundado na satisfação de necessidades privadas, sejam elas materiais ou não materiais. 0 segundo, não menos importante, é o aumento da justiça social. Neste caso, entra em cena a esfera pública, onde receberão atenção as necessidades dos grupos sociais, construindo-se o substrato sobre o qual se desenvolve a qualidade de vida (SOUZA, 2010, p. 61-64).

Os grupos sociais envolvidos devem, eles próprios, definir que caminhos escolher e quais prioridades eleger na busca pelos objetivos acima, objetivos sempre subordinados à autonomia individual e coletiva (p. 66).

À noção de justiça social estão associados parâmetros que são dela indissociáveis: o nível de segregação residencial, o grau de desigualdade socioeconômica e o grau de oportunidade para participação cidadã em processos decisórios relevantes (p. 67). Este último, diretamente relacionado com as ações práticas vinculadas ao planejamento territorial.

Ao tomar-se o desenvolvimento sócio-espacial como algo desejável, é imperativo salientar que justiça social e qualidade de vida são objetivos complementares. Nesse sentido, não se está pensando corretamente o desenvolvimento sócio-espacial se qualquer destes dois aspectos for, em algum nível, negligenciado ( $p$. 72). As ações de planejamento, portanto, e como nunca são neutras (p. 83), precisam distanciar-se do perfil mercadófilo e propor estratégias pró-desenvolvimento sócio-espacial.

\section{Fundamentos e objetivos da ação}

Os interessados em pleitear os recursos oferecidos na ação 8874, que são provenientes do Orçamento Geral da União (OGU), devem observar as orientações constantes no manual elaborado pelo Ministério das Cidades que divulga a ação aos entes federativos.As diretrizes da ação são bastante amplas, no que se refere à gestão e ao planejamento urbanos, mas não existem atividades de envolvimento direto do Ministério ou direcionadas a aplicações pré-estabelecidas. A seguir, no Quadro 1, são apresentados os principais focos de interesse.

\section{Quadro 1 - Focos de interesse}

- universalização do acesso à terra urbanizada, regularizada e bem localizada
- funções sociais da cidade e da propriedade
- estudos e metodologias para planejamento e gestão urbanos
- Planos Diretores Municipais e de Desenvolvimento Urbano Integrado
- instrumentos do Estatuto da Cidade
- combate à especulação imobiliária
- Política Nacional de Desenvolvimento Urbano
- planejamento e gestão das áreas de expansão urbana
- prevenção de riscos, regularização fundiária e provisão habitacional
- planejamento participativo e gestão democrática
- cooperação e integração entre estados e municípios
- articulação entre programas, ações e recursos

Fonte: Manual da Ação 8874 do Ministério das Cidades, compilação do autor

Cabe aos municípios e estados a iniciativa de apresentar propostas e buscar os recursos disponíveis, e compete ao Ministério das Cidades o papel de indutor, uma vez que este último não executa diretamente as atividades de planejamento e gestão, mas atua estimulando o desenvolvimento de programas municipais e estaduais voltados ao tema.

Percebe-se claramente esse cunho apenas de 
apoio nas palavras presentes nas diversas diretrizes elencadas, tais como: promover, contribuir, sensibilizar, estimular, potencializar, articular e auxiliar. Assim, podemos deduzir duas situações através da relação entre instâncias do Estado proposta pela ação 8874. Em primeiro lugar, muitos estados e municípios precisam fazer uso de recursos da União para desencadear com alguma qualidade atividades e programas de gestão e planejamento, mesmo sendo os responsáveis mais diretos por essa atuação. Além disso, mesmo tendo essa prerrogativa, há uma necessidade de estimular a procura por capacitação e implantação metodológica, o que remete à inferência de determinado grau de incapacidade técnica.

Para concretizar o apoio proposto na ação, cinco modalidades de implementação (elencadas no Quadro 2) são oferecidas, destinando-se ao fornecimento de assistência técnica (duas), capacitação (uma) e desenvolvimento de metodologias (duas), tendo como objetos os Planos Diretores (elaboração e revisão), os instrumentos de planejamento e gestão urbanos, os Planos de Expansão Urbana e planos de desenvolvimento urbano integrado.

\section{Quadro 2 - Modalidades de implementação}

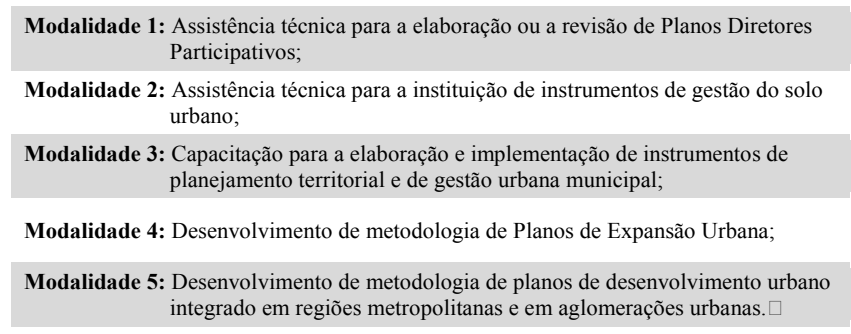

Fonte: Manual da Ação 8874 do Ministério das Cidades

Aqui, as diretrizes relacionadas no manual da ação passam a se limitar a mecanismos mais restritos, vinculados a planos e instrumentos específicos, mantendo o leque de alternativas mais discreto, além de já utilizar os mecanismos consagrados de planejamento e gestão que o Estatuto da Cidade define, o que direciona a conduta de estados e municípios através da legislação federal norteadora. Isso, de forma contraditória, limita as opções para a autonomia local, mas ao mesmo tempo garante o alinhamento ao que foi definido como rumo a seguir na escala nacional.

\section{Atores: preponderância do Estado}

Este rumo projetado para o ordenamento territorial tem como ator centralizador o Estado, seja em instância nacional (propondo e desencadeando a ação em questão) ou hierarquicamente inferior (que adere ao sistema de subsídio para implantação). Rosière (2007), quando discorre sobre os diferentes atores políticos, classifica o Estado como ator "clássico", diferenciando- -o da noção de governo. Necessita, para sua materialização, de uma estrutura, de uma autoridade e de um território (Rosière, 2007, p. 289). Assim, a gestão do território é certamente muito cara à administração pública, consistindo em um dos motivos para a proposição pela administração centralizada da ação 8874 . Não é claro, contudo, o caráter permanente desta política pública, o que impossibilita a sua caracterização como de estado ou de governo.

Outros atores necessariamente estarão envolvidos na construção de planos diretores ou outros instrumentos associados, mas no momento de apresentação de propostas para a busca dos recursos esses elementos não participam diretamente das decisões sobre demandas ou necessidades locais. Por isso, mesmo que os processos posteriores sejam participativos, a decisão de busca por apoio e consultoria é eminentemente estatal, restando aos demais atores uma participação posterior, reduzindo em algum grau a autonomia das coletividades envolvidas. Entre esses atores, Rosière aponta a Igreja também como ator clássico, e atores considerados novos, como os partidos políticos, ONGs e atores econômicos. Destes, os partidos políticos também têm participação direta quando da adesão à ação, reforçando a ideia de que se trata de uma política de governo. Uma vez melhor institucionalizada e passando por todos os trâmites legislativos (como projeto de lei, por exemplo), poderemos pensar nela como prática de Estado.

\section{Participação e descentralização: poderes central e local}

Como vivemos em uma sociedade democrática, a sociedade civil reivindica mais participação nas decisões, já afirma Costa (1988). Para este autor, surge disso uma oposição entre o poder central e os poderes locais, o que acaba criando a necessidade de rediscussão do problema federativo brasileiro. A ação 8874 é gerada inteiramente a partir da iniciativa do poder central, para então ser conduzida pelos poderes locais a partir das orientações emanadas a partir da centralidade do poder, vinculadas à legislação federal. Assim, a relação da sociedade civil com as formas institucionalizadas do poder acaba obedecendo à racionalidade do Estado em sua estrutura. Por outro lado, ajuda a manter a coesão estrutural da federação, ainda com vários traços de verticalidade.

A leitura preocupada com a descentralização também encontra eco na política pública estudada, onde, mesmo centralizando o controle e a racionalidade, transparece a tentativa de ceder aos municípios a prerrogativa da adesão e a condução das discussões locais. Silva e Costa (1995) defendem a descentralização, afirmando que aumenta a eficiência e diminui as disparidades regionais (p. 261). De acordo com estes autores, a origem do impulso descentralizador é indutiva (de origem estatal), e não reativa (societal), o que reforça a 
avaliação anterior de que há controle centralizado.

Avaliando a situação com preocupação em relação ao conflito federativo, esse controle ajuda a manter a coesão e minimizar possíveis competições entre municípios e regiões metropolitanas, que poderiam tender a flexibilizar suas diretrizes de planejamento urbano para obter algumas vantagens competitivas, algo análogo à guerra fiscal.

A ação 8874 é particularmente difícil de ser enquadrada em um dos dois paradigmas de descentralização avaliados por Silva e Costa (1995). Em um primeiro momento, parece realmente um estímulo à reestruturação da abordagem territorial (urbana), propondo a participação da sociedade civil nas discussões, o que tende a reduzir desigualdades e tornar a regulação mais respaldada socialmente e mais eficaz. Ao mesmo tempo, é preciso lembrar que no campo de poderes da sociedade civil as estratégias setoriais voltadas para o mercado assumem grande relevância. Por isso, também é possível identificar o que os autores definem como a "devolução", à sociedade, do controle estatal.

\section{Interesses setoriais}

Vale lembrar que as políticas setoriais são mais impactantes no território do que as políticas territoriais - pelo menos, seus resultados são mais rápidos. Dessa forma, é necessário limitar a cooptação, pelos setores econômicos, das lideranças que conduzirão a aplicação da política pública, o que não recebe adequado espaço no manual avaliado.

Sem definir centralmente a composição de forças e seus poderes no que diz respeito à participação nas decisões, há o risco de que, na definição dos eixos estratégicos que nortearão o planejamento municipal, alguns grupos pautem aquilo que o manual chama de "Leitura da Realidade Municipal", principalmente condicionando as definições de demandas de acordo com interesses setoriais. Sánchez (1992) lembra que a política territorial se configura também pelas "(...) formulações de atuação dirigidas a intervir sobre o território, a fim de que se assuma as formas que sejam adequadas ao conjunto dos interesses que controlam o poder político" (Sánchez, 1992, p. 72).

0 combate à especulação imobiliária, objetivo da ação, passa por esse entendimento, já que o setor da construção civil e o setor financeiro-imobiliário tendem a monopolizar outro objetivo, que é a participação. Por isso, a vinculação da liberação de recursos à comprovação, através de estudos independentes, de que os objetivos do planejamento municipal efetivamente primam pela redução das desigualdades seria salutar, e atenderia a um dos principais objetivos propostos na ação.

\section{Ordem interna e desenvolvimento}

Feitas as ressalvas mais imediatas, podemos afir- mar que a ação 8874 integra um conjunto de políticas que, como defende Costa (2005), reforça o sentido de coesão do território, através do estímulo ao ordenamento territorial. 0 ordenamento, para este autor, busca “(...) traçar os contornos básicos das suas políticas regionais e ambientais, principalmente" (COSTA, 2005, p. 9).

A grande importância estratégica do ordenamento reside na ordem interna, necessária para o exercício do poder pelos estados. Dessa forma, mais do que tentar alcançar uma situação de menores desigualdades sociais, o ordenamento permite o controle dos territórios. Resta saber se a redução das desigualdades é um objetivo de estado e não somente de governo, o que pode realmente ser observado no Brasil, desde que respeitados os preceitos da Constituição, onde o tema é abordado diretamente.

Para a manutenção da coesão e do controle, é importante controlar a linha de tensão que Costa (2005) identifica entre os objetivos estratégicos (centralizados) e as aspirações locais. Assim, a política pública centralizada de oferecer apoio ao planejamento e ao ordenamento territoriais reforça o controle sobre o território, e ao mesmo tempo permite que as coletividades locais discutam e consolidem os instrumentos da política urbana em conformidade com suas aspirações.

Outro objetivo central elencado é o desenvolvimento urbano, que tem predominância de uma componente territorial. Baudelle (2011) define o desenvolvimento territorial como "(...) um processo voluntarista que busca aumentar a competitividade dos territórios envolvendo os atores através de ações integradas, geralmente transversais e com forte dimensão espacial" (BAUDELLE, 2011, p. 22).

0 que se entende por desenvolvimento, no entanto, pode ter várias interpretações, dependendo dos interesses envolvidos. No caso da Política Nacional de Desenvolvimento Urbano (PNDU), conduzida também pelo Ministério das Cidades, e que pauta os trabalhos da ação 8874, a ideia inicial era conduzir um processo amplo, com a participação ativa da sociedade civil, mas mudanças políticas, de gestão e metodológicas produziram distorções. 0 exemplo mais saliente é o Programa Minha Casa Minha Vida (PMCMV), que ainda gera muitas discussões sobre a efetividade da busca por justiça social ou o simples (nem tanto) reforço à reprodução do capital de alguns setores da economia. Vinculado a essa política, a ação estudada pode tomar o mesmo rumo, caso não sejam definidos mais claramente esses detalhes.

\section{Escalas de abordagem}

Aspecto importante na definição de Baudelle é a "competitividade dos territórios", que depende de um processo voluntarista produtor de desenvolvimento territorial e que ganha forma através de ações concertadas, transversais e com forte dimensão espacial. Esta 
dimensão, no entanto, pode assumir contornos diferenciados dependendo da escala de análise.

Para conduzir uma pesquisa ou mesmo, como neste caso, analisar um documento, Racine et al. (1983) recomenda que a escala seja explicitada. Os autores criticam as abordagens que trabalham as dimensões escalares isoladamente, além de apresentar a escala como "mediadora entre a intenção e a ação" (RACINE et al., 1983, p. 133).

Também Lacoste (2002) oferece elementos para melhorar a compreensão, quando afirma que um mesmo fenômeno pode se comportar de maneiras diferentes dependendo da escala. É imperativo, no entanto, integrar variados níveis escalares, atravessados pelos processos de interesse para a análise.

Dessa forma, a contradição entre as aspirações locais e a política nacional podem ser melhor entendidas. Quando Baudelle fala em competitividade dos territórios como necessária para o desenvolvimento territorial, há que se acrescentar a questão da escala. Analisando o território local em si, o aumento de competitividade pode contribuir para a construção de avanços rumo à diminuição de desigualdades, desde que as aspirações setoriais não monopolizem a pauta. Então, a coesão interna pode ser consolidada. No entanto, se a competitividade se traduzir em uma busca por oferecer melhores vantagens competitivas a setores da economia e competir (neste caso, competição) com outras unidades da federação por instalações capitalistas dinâmicas, o resultado pode ser a desestruturação da coesão nacional.

É possível, por isso, estabelecer uma contradição entre, de um lado, a tentativa de melhorar o controle do território e de estimular a equidade e, de outro, a dificuldade de emplacar uma das diretrizes da ação 8874, que é a cooperação interfederativa. Essa cooperação tende a ocorrer, mas apenas entre municípios da própria unidade federativa, não sendo garantida a cooperação interestadual nem intermunicipal, quando os municípios em questão não integram a mesma região metropolitana.

Portanto, oferecer apoio técnico e distribuir recursos devem ser práticas posteriores às discussões (locais e nacionais), visto que a prerrogativa de pleitear recursos e propor a adesão é, na maior parte das vezes, do chefe do Poder Executivo.

\section{Considerações finais}

Consistindo em um grande avanço no sentido de proporcionar condições técnicas para que municípios possam elaborar seus planejamentos urbanos, a ação 8874 precisa estar associada à garantia de que as propostas escolhidas e os recursos destinados o sejam através de critérios técnicos que primem pela integração dos grupos sociais (principalmente os menos favorecidos) nas discussões não somente da condução de planos com metodologias pré-concebidas, mas também sobre o que entendem como desenvolvimento urbano.

Tanto o apoio técnico quanto a destinação de recursos podem apenas reforçar as tendências metodológicas centrais, que muitas vezes estão descoladas das necessidades locais, ou consolidar as práticas já consagradas localmente que nem sempre garantem a efetiva participação dos diferentes grupos na criação de autonomia com justiça social. Assim, um passo anterior que não pode ser ignorado é a construção de interações que produzam coletivamente as ideias norteadoras daquilo que se espera com o planejamento. Estabelecido esse processo e superada essa etapa, ações como a 8874 tem condições de integrar propostas centrais e aspirações locais com mais eficácia e garantindo melhores resultados no enfrentamento das dificuldades de superação dos problemas urbanos das cidades brasileiras.

\section{Referências}

BAUDELLE, Guy et alii. Le développement territorial en Europe. Concepts, enjeux et débats. Rennes: Presses Universitaires de Rennes, 2011.Capítulo 1. Le développement territorial: finalités et spécificités, 2011, p. 13-27.

BRASIL. Ministério das Cidades. Programa Planejamento Urbano. Sistemática 2012. Ação 8874: Apoio ao planejamento territorial e à gestão urbana municipal e interfederativa (manual da ação). Disponível em:

<http://www.cidades.gov.br/images/stories/Sistematicas/2012/Manual_de_Planejamento_Territorial_2012-2. pdf> Acesso em: 12 jun 2012.

BRASIL. Ministério das Cidades. Portaria no 87, de 24 de fevereiro de 2012. Diário Oficial da União. Poder Executivo, Brasília, DF, 27 de fevereiro de 2012. Seção 1. p. 54. Protesto paralisa centro de Porto Alegre. CORREIO DO POVO, Porto Alegre, 18 jun 2013. Notícias. Disponível em : < http://www.correiodopovo.com.br/ Noticias/?Noticia=501077> Acesso em: 18 jun 2013.

COSTA, Wanderley M. da. O Estado e as políticas territoriais no Brasil. São Paulo: Edusp: Contexto, 1988.

COSTA, Wanderley M. da. Política e território em tempos de mudanças globais, Tese de Livre-Docência, São Paulo, 2005.

LACOSTE, Yves. A geografia: isso serve, em primeiro lugar, para fazer a guerra. 6.ed. Campinas: Papirus, 2002.

NYGAARD, Paul Dieter. Planos diretores de cidades: discutindo sua base doutrinária. Porto Alegre: UFRGS, 2005.

RACINE, J. B., RAFFESTIN, C.; RUFFY, V. Escala e ação, contribuições para uma interpretação do mecanismo de escala na prática da Geografia. Revista Brasileira de Geografia,v.45, n.1, p. 123-135, jan.-mar. 1983.

ROSIÈRE, Stéphane. Géographie Politique \& Géopolitique. Une grammaire de l'espace politique. $2^{\text {a }}$ édition. Paris: Ellipses. 2007, p. 283-346. 
SANCHEZ, Joan-Eugeni. Geografia Política. Madrid: Editorial Síntesis. 1992. Capítulo 3. Âmbitos de la geografía política.

SOUZA, Marcelo Lopes de. Mudar a cidade: uma introdução crítica ao planejamento e à gestão urbanos. Rio de Janeiro: Bertrand Brasil, 2010, 7 ed.

SILVA, Pedro Luis B.; COSTA, Vera Lúcia C. Descentralização e crise da Federação. In: AFFONSO, Rui de Britto

Álvares (Orgs.). A federação em perspectiva. Ensaios selecionados. São Paulo: Fundap-Unesp, 1995, p. 261-283.

\section{Referências de apoio}

BOBBIO, Norberto. O conceito de sociedade civil. Rio de
Janeiro: Graal, 1982.

CASTRO, Iná E. de. Geografia e política. Território, escalas de ação e instituições. Rio de Janeiro: Bertrand-Brasil, 2005. Capítulo 3. O poder e o poder político como problemas.

COX, Kevin. Redefining "territory". Political Geography Quarterly, v. 10, n.1, p. 5-7, jan. 1991.

FIORI, José Luis. Para repensar o papel do Estado sem ser um neoliberal. Revista de Economia Política, v. 12, n. 1, p. 76-89, jan-mar 1992.

RAFFESTIN, Claude. Por uma geografia do poder. São Paulo: Ática, 1993.

\title{
PUBLIC POLICY ANALYSIS: FEDERAL MINISTRY OF CITIES' ACTION 8874
}

\begin{abstract}
The Federal Ministry of Cities' action 8874 was launched in 2012 to help promote the territorial regulation through urban planning and management driven by states and municipalities, who are encouraged to qualify master plans, land management and land planning. However, a number of elements need to be further studied to make possible evaluate if the ideas produced centrally and local aspirations are mutually contemplated by the benefits originated by resources that the action provides. The applied methodology provides a theoretical discussion on the topic of the public policy in question, choosing authors linked to related topics, with the objective to stimulate discussion about ways of directing the activities of planning. This essay promotes discussion of topics like the actors involved, participation, sectorial interests, territorial cohesion and scales approach, revealing the need for joint and collective constructions prior to the adhesion by federative entities.
\end{abstract}

Keywords: territorial planning, urban management, development, public policies.

\section{ANÁLISIS DE POLÍTICA PÚBLICA: ACCIÓN 8874 DEL MINISTERIO DE LAS CIUDADES}

Resumen: La acción 8874 del Ministerio de las Ciudades fue lanzada en 2012 para ayudar a promover la ordenación del territorio mediante la planificación y la gestión urbana impulsados por los estados y municipios, que son estimulados a calificar los planes directores, la gestión del suelo y la planificación del territorio. Sin embargo, una serie de elementos necesita ser más estudiada para que pueda evaluar si las ideas producidas en el centro y las aspiraciones locales están mutuamente contempladas por los beneficios derivados de los recursos que la acción ofrece. La metodología aplicada proporciona una discusión teórica sobre el tema de la política pública en cuestión, por la elección de autores conectados com los temas relacionados, con el fin de estimular el debate sobre las formas de dirigir las actividades de planificación. Este ensayo promueve la discusión de tópicos como los actores implicados, participación, intereses sectoriales, la cohesión territorial y escalas de abordaje, revelando la necesidad de construcciones conjuntas y colectivas previas a la adhesión de las entidades federativas. Palabras clave: planificación territorial, gestión urbana, desarrollo, políticas públicas. 